\title{
Comparison of thermodynamic database models and APT data for strength modeling in high Nb content $\gamma-\gamma$ ' Ni-base superalloys
}

Stoichko Antonov ${ }^{\mathrm{a}, *}$, Martin Detrois ${ }^{\mathrm{a}}$, Dieter Isheim ${ }^{\mathrm{b}, \mathrm{c}}$, David Seidman ${ }^{\text {b,c }}$, Randolph C. Helmink

${ }^{\mathrm{d}}$, Robert L. Goetz ${ }^{\mathrm{d}}$, Eugene Sun ${ }^{\mathrm{d}}$, Sammy Tin ${ }^{\mathrm{a}}$

${ }^{a}$ Illinois Institute of Technology, $10 \mathrm{~W} .32^{\text {nd }}$ Street, Chicago, IL 60616, USA

${ }^{b}$ Department of Materials Science and Engineering, Northwestern University, 2220 Campus Drive, Evanston, IL 60208, USA

${ }^{c}$ Northwestern University Center for Atom Probe Tomography (NUCAPT), 2220 Campus Drive, Evanston, IL 60208, USA

${ }^{d}$ Rolls-Royce Corporation, PO Box 420, Indianapolis, IN 46241, USA

* Corresponding author. E-mail address: santonov@hawk.iit.edu

\begin{abstract}
In response to the increasing need for higher operating temperatures in advanced gas turbine engines, new alloying concepts are required to develop novel nickel-base superalloys with enhanced temperature capabilities. Recent studies have shown that polycrystalline Ni-base superalloys containing elevated levels of $\mathrm{Nb}$ additions exhibit superior properties at elevated temperatures when compared to existing commercial Ni-base superalloys. In order to design, develop and fully exploit this innovative class of superalloys, an understanding of how alloying elements partition to each phase is essential. Using atom probe tomography (APT), compositions of the constituent phases were measured in four high $\mathrm{Nb}$ content $\gamma-\gamma$ ' Ni-base superalloys and the results were compared to thermodynamic database models from Thermo-Calc. Results were also used in predicting the solid solution strength behavior of the four alloys. The differences in phase composition predictions from thermodynamic models resulted in dissimilarities between the generated strength behavior curves and those from the experimental work.
\end{abstract}

Keywords- Superalloy, Partition, Atom Probe Tomography, Thermo-Calc, Strengthening 


\section{Introduction}

High strength combined with considerable fatigue resistance and the ability to survive in corrosive environments at elevated temperatures are key properties that make nickel-based superalloys the material of choice for use in the "hot section" of modern gas turbine engines for power generation, aerospace and marine propulsion applications [1-9]. The superior high temperature properties of Ni-base superalloys can largely be attributed to the unique microstructure consisting of ordered $\mathrm{L1}_{2}$ intermetallic precipitates, $\gamma^{\prime}\left(\mathrm{Ni}_{3} \mathrm{Al}\right)$, distributed coherently within a disordered FCC A1 matrix, $\gamma(\mathrm{Ni})$, that provides substantial order and coherency type strengthening by restricting dislocation motion during plastic deformation. In modern polycrystalline Ni-base superalloys, refractory alloying elements such as $\mathrm{W}, \mathrm{Mo}, \mathrm{Cr}$ and Co confer strength to the $\gamma$ matrix phase through solid solution strengthening, while additions of $\gamma^{\prime}$ forming elements ( $\mathrm{Al}, \mathrm{Ti}, \mathrm{Nb}$ and $\mathrm{Ta}$ ) are utilized to produce an optimized volume fraction of the $\gamma^{\prime}$ strengthening phase. Although modest improvements in the temperature capability and strength of the alloy can be attained via an increase in the volume fraction of the $\gamma^{\prime}$ precipitates, this tends to degrade processing capabilities and environmental resistance while increasing the overall alloy cost.

When designing new variants of Ni-base superalloys, additions of $\mathrm{Nb}$, Ta and Ti to $\gamma-\gamma$ ' Ni-base superalloys can greatly effect the microstructure of the alloy and the levels of these alloying additions have to be carefully optimized. Relatively low alloying concentrations of $\mathrm{Nb}$, Ta, and/or Ti will preferentially partition to the $\gamma^{\prime}$ phase and serve to lower the anti-phase boundary energy as well as to strengthen the precipitate's resistance to deformation [10]. However, as the overall concentrations of these elements increases to just below the solubility limit, residual partitioning to the $\gamma$ phase saturates the matrix with potent solid solution strengtheners $[11,12]$. This may potentially be used to enhance the strength and temperature capability of the alloy, but excessive alloying with $\mathrm{Nb}$, Ta and $\mathrm{Ti}$ can promote the formation of 
undesirable secondary phases such as $\delta\left(\mathrm{Ni}_{3} \mathrm{Nb}\right)$ and/or $\eta\left(\mathrm{Ni}_{6} \mathrm{AlNb}\right)$ within the microstructure when the solubility limits are exceeded [13-15]. Although the effect of individual alloying additions on $\delta$ and/or $\eta$ phase precipitate formation has been previously investigated [16,17], the characteristic partitioning behavior of the elements between the $\gamma$ or $\gamma^{\prime}$ phases in high $\mathrm{Nb}$ content Ni-base superalloys is not well understood. In order to develop high strength polycrystalline $\mathrm{Ni}$ base superalloys with improved temperature capabilities, a fundamental understanding of the alloying solubility limits and equilibrium phase compositions is required.

Thermodynamic database models such as Thermo-Calc or Computherm Pandat have been demonstrated to be effective in predicting the multicomponent thermodynamic stability of complex phases in commercial and experimental alloys with compositions that fall within the range of alloys over which substantial experimental data exists and these thermodynamic predictions can greatly accelerate the development and optimization of modified alloy compositions $[18,19]$. In the case of highly alloyed Ni-base superalloys, the capability of these models to accurately predict microstructural stability becomes challenged as experimental alloy compositions become more complex and incorporate higher concentrations of alloying additions. Due to the limited amount of experimental thermodynamic data on the partitioning of $\mathrm{Nb}$ and $\mathrm{Ta}$ in the $\gamma-\gamma^{\prime}$ alloy system, the precision of thermodynamic database models is lacking, and an improved fundamental understanding of how the different elemental alloy additions partition to $\gamma$ and $\gamma^{\prime}$ phases and their effect on the microstructure and the properties of this novel class of $\mathrm{Ni}$ base superalloys is needed in order to design and successfully implement Ni-base superalloys with improved properties.

The development of predictive, physics-based strength models for Ni-base superalloys has helped elucidate the effects of microstructure and intrinsic chemistry of the alloy on the strengthening behavior. Using these established models for solid solution strengthening and $\gamma^{\prime}$ 
hardening, the present investigation compares the differences in results when using Thermo-Calc predictions as inputs versus actual measurements of the phase compositions and distributions obtained by APT and microstructural analysis in four experimental $\gamma-\gamma$ ' Ni-base superalloys. In addition, the preferential partitioning of elemental alloying additions to a given phase was reported from the APT data and again compared to the Thermo-Calc predictions.

\section{Model}

The present report focuses on the effect of compositional strengthening; therefore, among the various strengthening mechanisms that are present in Ni-base superalloys, only solid solution strengthening and $\gamma^{\prime}$ hardening models were considered. The solid solution strengthening of the alloys was modeled using the method of Gypen and Deruyttere [11,12,20,21] shown in Eq. (1).

$\Delta \sigma=\left(\sum_{i} \frac{d \sigma}{d \sqrt{C_{i}}}{ }^{\frac{1}{n}} C_{i}\right)^{n}$

In Eq. (1), $\mathrm{n}$ is taken to be $0.5, \mathrm{C}_{\mathrm{i}}$ is the concentration of solute $i$, and $\frac{d \sigma}{d \sqrt{C_{i}}}$ is the strengthening constant for solute $i$. In order to express the solid solution strength in terms of temperature, the Feltham expression has been used, in Eq. (2) [12].

$T\left(\frac{\tau}{\mu}\right)^{\frac{1}{2}}=K_{1}-K_{2} \tau$

In Eq. (2), $K_{1}$ and $K_{2}$ are alloy constants, $T$ is the temperature, $\mu$ is the shear modulus and $\tau$ is the shear stress. Similarly, the cross slip pinning operating within the larger $\gamma$ ' precipitates, which further strengthens the alloys, is modeled using Eq. (3) [11,21,22].

$\Delta \sigma=f\left[\sigma(T)_{N i_{3} A l}+\sum_{i}\left(\frac{d \sigma}{d C_{i}} C_{i}\right)\right]$ Eq. (3)

In Eq. (3), $\mathrm{f}$ is the fraction of precipitates that are subjected to cross-slip induced hardening, $\sigma(\mathrm{T})_{\mathrm{Ni3}} \mathrm{Al}$ is the strength of pure $\mathrm{Ni}_{3} \mathrm{Al}$ as a function of temperature, $\mathrm{C}_{\mathrm{i}}$ is the concentration of 
solute $i$, and $\frac{d \sigma}{d C_{i}}$ is the strengthening constant for solute $i[22,23]$. The lattice friction stress represents the overall resistance of the lattice to dislocation motion and is dependent on temperature, strain, alloy and impurity content. Solute atoms in both the matrix and precipitates give rise to frictional resistance to dislocation motion and therefore strongly affect the lattice friction stresses. The value of shear stress required to initiate slip is referred to as the critical resolved shear stress (CRSS) and Rao et al., determined the CRSS for a pair of $60^{\circ}$ mixedcharacter dislocations as a function of frictional stress, in both the matrix and the precipitates [2426]. Values for the friction stress calculated with Eqs. 1, 2 and 3 were used to calculate the CRSS using the plot in Fig. 1 [21,27].

\section{Methods and Materials}

Four experimental Ni-base superalloys, RRHT1, RRHT2, RRHT3, and RRHT4, were used in this investigation, Table 1. The actual compositions of the alloys are not disclosed but the levels of $\mathrm{Cr}$, Mo, Ta and $\mathrm{W}$ are nominally identical for all four alloys and fall within the ranges specified in Table 1. The actual, measured concentrations of $\mathrm{Al}, \mathrm{Co}$ and $\mathrm{Nb}$ in the RRHT alloys are reported in Table 1 and were systematically varied to elucidate the effects of these elements on the microstructure and partitioning characteristics. All of the samples were isothermally forged from a hot isostatically pressed (HIP) billet and solution heat treated at $1170^{\circ} \mathrm{C}$ for $1 \mathrm{~h}$, followed by a controlled cooling rate of $1{ }^{\circ} \mathrm{C} / \mathrm{s}$. The samples were subsequently aged at $850^{\circ} \mathrm{C}$ for $4 \mathrm{~h}$ and furnace cooled. Metallographic samples were prepared using standard grinding and polishing techniques to a final polishing using a solution of $0.06 \mu \mathrm{m}$ colloidal silica. The samples were etched using a $33 \% \mathrm{HCL}-33 \% \mathrm{NO}_{3}-33 \% \mathrm{CH}_{3} \mathrm{COOH}-1 \% \mathrm{HF} \gamma^{\prime}$ etchant for observation under a JEOL JSM 6701-F field emission scanning electron microscope (FESEM) in secondary electron (SE) mode with an accelerating voltage of $10 \mathrm{kV}$. Ten distinct images of the microstructure were 
taken at 20,000x in different regions of each sample in order to obtain a good representation of the $\gamma^{\prime}$ phase distribution. The software ImageJ was used to determine the area fraction and feret size of the $\gamma^{\prime}$ phase in each alloy.

For preparation of specimens for atom probe tomography (APT), thin sheet specimens were prepared by grinding the samples to $\sim 8 \mathrm{~mm} \times 14 \mathrm{~mm} \times 0.3 \mathrm{~mm}$ dimensions for each alloy. Square rods of cross section measuring $\sim 0.34 \times 0.34 \mathrm{~mm}$ were cut from the thin sheets using a high speed diamond saw. These thin rods were subsequently electro-polished into needles with an approximate tip diameter of $100 \mathrm{~nm}$. The electro-polishing was done using a two steps sequence: first a coarse polish was performed using a $10 \%$ perchloric acid in acetic acid solution at about 25 $\mathrm{V}$, and second, a fine polish was done using a $2 \%$ perchloric acid in butoxyethanol solution at about $19 \mathrm{~V}$. APT was conducted using an IMAGO 3D LEAP4000XSi local electrode tomograph with a picosecond ultraviolet (wavelength of $355 \mathrm{~nm}$ ) laser energy of $20 \mathrm{pJ}$ per pulse, a pulse repetition rate of $500 \mathrm{kHZ}$, a microtip temperature of $34 \mathrm{~K}$ and an evaporation rate of $5 \%$. All of the APT data was analyzed using IVAS 3.6.2 software from Cameca.

Table 1. Composition of the RRHT alloys (at.\%).

\begin{tabular}{lllllllll}
\hline Alloy & Ni & Cr & Al & Mo & Co & Nb & Ta & W \\
\hline RRHT1 & Bal. & $5-16$ & 7.94 & $0-3$ & 18.37 & 5.54 & $0-3$ & $0-2$ \\
RRHT2 & Bal. & $5-16$ & 7.95 & $0-3$ & 12.67 & 5.59 & $0-3$ & $0-2$ \\
RRHT3 & Bal. & $5-16$ & 9.81 & $0-3$ & 18.25 & 4.63 & $0-3$ & $0-2$ \\
RRHT4 & Bal. & $5-16$ & 9.46 & $0-3$ & 11.91 & 4.70 & $0-3$ & $0-2$ \\
\hline
\end{tabular}

\section{Results}

The micrographs in Fig. 2 reveal the typical $\gamma-\gamma^{\prime}$ microstructure of each of the four alloys. Results from the image analysis are compiled in Table 2 and show that RRHT1 and RRHT2 exhibit similar volume fractions of $\gamma^{\prime}$ precipitates at $\sim 4 \%$, while RRHT3 and RRHT4 had slightly higher amount of $\gamma^{\prime}$ precipitates compared to RRHT1 and RRHT2 at $\sim 49 \%$. In order to 
differentiate between secondary and tertiary $\gamma^{\prime}$ precipitates, and establish a minimum size threshold for precipitate hardening, any precipitate smaller than $90 \mathrm{~nm}$ was considered to be tertiary $\gamma^{\prime}$. The threshold value of $90 \mathrm{~nm}$ was determined following analysis of the micrographs from all four alloys. Calculation of the average precipitate sizes revealed that RRHT1, RRHT2, and RRHT3 have similar secondary $\gamma^{\prime}$ precipitate sizes of around $260 \mathrm{~nm}$, while RRHT4 contained much coarser precipitates measuring approximately $358 \mathrm{~nm}$. The tertiary $\gamma^{\prime}$ precipitates for all of the alloys represent about $1 \%$ of the total volume fraction of precipitates and on average had a particle size of about $60 \mathrm{~nm}$ for RRHT1 and RRHT2 and $53 \mathrm{~nm}$ for RRHT3 and RRHT4. It should be mentioned that, some of the very fine tertiary $\gamma^{\prime}$ precipitates $(<10 \mathrm{~nm})$ may not have been resolved during image analysis. Although the influence of these very fine precipitates on the $\gamma$ ' volume fraction would be negligible, they potentially could have a larger effect on the mean tertiary particle size.

Table 2. Volume fraction and size of $\gamma^{\prime}$ precipitates for the RRHT alloys measured using ImageJ.

\begin{tabular}{lllll}
\hline Alloy & $\begin{array}{l}\text { Volume fraction of } \\
\text { Y' precipitates } \mathbf{( \% )}\end{array}$ & $\begin{array}{l}\text { Average secondary } \mathbf{Y}^{\prime} \\
\text { size }(\mathbf{n m})\end{array}$ & $\begin{array}{l}\text { Volume fraction of } \\
\text { tertiary Y' (\%) }\end{array}$ & $\begin{array}{l}\text { Average tertiary } \mathbf{Y}^{\prime} \\
\text { size }(\mathbf{n m})\end{array}$ \\
\hline RRHT1 & $43.7+/-2.9$ & $257+/-11$ & $1.0+/-0.2$ & $59.5+/-1.7$ \\
RRHT2 & $43.7+/-1.8$ & $261+/-21$ & $1.1+/-0.4$ & $59.2+/-3.4$ \\
RRHT3 & $48.7+/-1.7$ & $263+/-13$ & $0.9+/-0.3$ & $56.0+/-4.8$ \\
RRHT4 & $48.1+/-2.2$ & $358+/-20$ & $1.1+/-0.4$ & $51.7+/-2.5$ \\
\hline
\end{tabular}

Multiple atom probe needles were analyzed for each of the alloys and the size of the dataset used for analysis of RRHT1, RRHT2, RRHT3 and RRHT4 ranged from 65 to 448 million atoms. Fig. 3 shows the 3D tomography of the $\gamma^{\prime}$ precipitates for each of the RRHT alloys where the interfaces were observed. For example, Fig. 3c, the RRHT3 needle comprised of 127 million atoms contained three discrete $\gamma-\gamma^{\prime}$ interfaces along secondary $\gamma^{\prime}$ precipitates and two small tertiary $\gamma^{\prime}$ precipitates. Note that only $\mathrm{Cr}$ atoms, in blue, and $\mathrm{Al}$ atoms, in red, are displayed as these partition strongly to the $\gamma$ and $\gamma^{\prime}$ phases, respectively, and so provide a better visual 
representation of the needle construction. An average of the phase composition was taken for each respective phase away from each interface and at least $25 \mathrm{~nm}$ into the phase. Only results from the secondary $\gamma^{\prime}$ precipitates was used as they are closer to the thermodynamic equilibrium. The results were averaged among the interfaces of each needle for each alloy and the results are provided in Table 3. Corresponding to the higher overall concentration of $\mathrm{Nb}$ present in the bulk alloy, approximately $\sim 8$ at. $\% \mathrm{Nb}$ was found in the $\gamma^{\prime}$ phase of RRHT1 and RRHT2 while $\sim 6$ at.\% $\mathrm{Nb}$ was present in the $\gamma^{\prime}$ phase of RRHT3 and RRHT4. Interestingly, $\mathrm{Nb}$ was also found to exhibit moderate solution in the $\gamma$ phase with $\sim 2$ at. $\%$ in the $\gamma$ phase of RRHT1, RRHT2, and RRHT4, and $\sim 1$ at.\% in the $\gamma$ phase of RRHT3. Similarly, the other $\gamma^{\prime}$ forming elements, primarily Ta and Al exhibited preferential segregation to the $\gamma^{\prime}$ phase at $\sim 1.5$ at.\% for Ta in all alloys and 13 at.\% and 15 at.\% for Al in RRHT1 and RRHT2, and RRHT3 and RRHT4, respectively. Consequently, the partition coefficient, $k=C_{\gamma} / C_{\gamma}$, for $\mathrm{Nb}$ was found to be $0.27,0.30$, 0.22 and 0.28 for RRHT1, RRHT2, RRHT3 and RRHT4, respectively. Within this set of RRHT alloys, the magnitude of these partition coefficients for $\mathrm{Nb}$ were at least double the partition coefficients of $\mathrm{Ta}(\sim 0.11)$ and $\mathrm{Al}(\sim 0.14)$. Alloying additions of Mo and $\mathrm{Cr}$, on the other hand, were found to partition preferentially to the $\gamma$ phase. The concentration of $\mathrm{W}$ and Co were found to be substantially higher in the $\gamma$ phase; however, considerable amounts were also found in the $\gamma^{\prime}$ phase. Similarly, elevated concentrations of $\mathrm{Cr}$ were observed in the $\gamma$ phase.

Table 3. $\gamma$ and $\gamma^{\prime}$ phase compositions obtained via APT (at.\%).

\begin{tabular}{lllllllll}
\hline \multirow{2}{*}{$\begin{array}{l}\text { Alloy } \\
\text { Element }\end{array}$} & RRHT1 & \multicolumn{3}{c}{ RRHT2 } & \multicolumn{3}{c}{ RRHT3 } & \multicolumn{3}{c}{ RRHT4 } \\
\cline { 2 - 8 } & $\begin{array}{l}\text { (at.\%) } \\
\text { (at.\%) }\end{array}$ & $\begin{array}{l}\text { Y }^{\prime} \\
\text { (at.\%) }\end{array}$ & $\begin{array}{l}\mathrm{Y}^{\prime} \\
\text { (at.\%) }\end{array}$ & $\begin{array}{l}\text { Y } \\
\text { (at.\%) }\end{array}$ & $\begin{array}{l}\mathrm{Y}^{\prime} \\
\text { (at.\%) }\end{array}$ & $\begin{array}{l}\text { Y } \\
\text { (at.\%) }\end{array}$ & $\begin{array}{l}\mathrm{Y}^{\prime} \\
\text { (at.\%) }\end{array}$ \\
\hline $\mathrm{Ni}$ & 38.3 & 62.8 & 48.7 & 68.4 & 36.8 & 64.0 & 43.8 & 66.5 \\
$\mathrm{Cr}$ & 28.8 & 1.8 & 26.3 & 1.5 & 28.9 & 1.9 & 29.1 & 1.7 \\
$\mathrm{Al}$ & 1.6 & 12.8 & 1.3 & 13.1 & 2.2 & 14.2 & 2.8 & 15.1 \\
$\mathrm{Mo}$ & 3.0 & 0.7 & 2.6 & 0.5 & 2.8 & 0.7 & 3.2 & 1.0 \\
$\mathrm{Co}$ & 24.3 & 10.6 & 16.9 & 6.8 & 26.3 & 10.9 & 17.6 & 7.2 \\
$\mathrm{Nb}$ & 2.1 & 8.0 & 2.3 & 7.7 & 1.3 & 5.9 & 1.8 & 6.3 \\
\hline
\end{tabular}




\begin{tabular}{lllllllll}
\hline $\mathrm{Ta}$ & 0.16 & 1.62 & 0.19 & 1.52 & 0.13 & 1.56 & 0.17 & 1.41 \\
$\mathrm{~W}$ & 1.17 & 0.53 & 1.24 & 0.47 & 1.21 & 0.59 & 1.19 & 0.64 \\
\hline
\end{tabular}

Additionally, Thermo-Calc simulations of phase fractions and compositions for these alloys were performed using the TCNI5 database. Only phases that were observed in the actual compositions were included in the simulations, namely $\gamma, \gamma^{\prime}$, and $\mathrm{MC}$ carbides, while phases such as $\delta, \eta$ and $\sigma$ were suppressed, as those were not observed in the microstructure of the alloys. The fraction plots, shown in Fig. 4, provide information about the equilibrium fraction of each phase present in the alloy at different temperatures. Comparison of the predicted phase fraction values for $\gamma^{\prime}$ at $850^{\circ} \mathrm{C}$ shown in Table 4 with the experimentally measured values, Table 2 , show reasonably good agreement.

Table 4. Volume fraction of $\gamma^{\prime}$ precipitates for the RRHT alloys from Thermo-Calc simulations.

\begin{tabular}{ll}
\hline Alloy & $\begin{array}{l}\text { Volume fraction of } \\
\text { Y' precipitates (\%) }\end{array}$ \\
\hline RRHT1 & 43.2 \\
RRHT2 & 44.9 \\
RRHT3 & 50.4 \\
RRHT4 & 51.9 \\
\hline
\end{tabular}

The phase compositions of each alloy were also obtained from Thermo-Calc simulations at $850^{\circ} \mathrm{C}$ and are shown in Table 5. The $\mathrm{Nb}$ concentration in the $\gamma^{\prime}$ phase is elevated for the higher Nb content alloys, RRHT1 and RRHT2, at approximately 9.5 at.\%, while RRHT3 and RRHT4, having a lower overall $\mathrm{Nb}$ content, are calculated to have $\sim 7$ at.\% $\mathrm{Nb}$ in the $\gamma^{\prime}$ phase. $\mathrm{The} \mathrm{Nb}$ content in the $\gamma$ phase was predicted to be relatively limited with RRHT1 having the highest concentration at 2.4 at.\% and RRHT4 having the lowest fraction at 1.4 at.\%, while RRHT2 and RRHT3 contained 1.7 at.\% Nb in the $\gamma$ phase. Similarly, the other $\gamma$ ' forming elements, primarily Ta and Al were predicted to preferentially segregate to the $\gamma^{\prime}$ phase at $\sim 1.6$ at. $\%$ for Ta in all 
alloys and 13 at.\% and 15 at.\% for Al in RRHT1 and RRHT2, and RRHT3 and RRHT4, respectively.

Table 5. $\gamma$ and $\gamma^{\prime}$ phase compositions obtained from Thermo-Calc (TCNI5) (at.\%).

\begin{tabular}{lllllllll}
\hline \multirow{2}{*}{$\begin{array}{l}\text { Alloy } \\
\text { Element }\end{array}$} & RRHT1 & \multicolumn{3}{c}{ RRHT2 } & \multicolumn{3}{c}{ RRHT3 } & \multicolumn{3}{c}{ RRHT4 } \\
\cline { 2 - 8 } & $\begin{array}{l}\text { (at.\%) } \\
\text { (at.\%) }\end{array}$ & $\begin{array}{l}\text { Y } \\
\text { (at.\%) }\end{array}$ & $\begin{array}{l}\text { Y' }^{\prime} \\
\text { (at.\%) }\end{array}$ & $\begin{array}{l}\text { Y } \\
\text { (at.\%) }\end{array}$ & $\begin{array}{l}\text { Y' }^{\prime} \\
\text { (at.\%) }\end{array}$ & $\begin{array}{l}\text { Y } \\
\text { (at.\%) }\end{array}$ & $\begin{array}{l}\text { Y' }^{\prime} \\
\text { (at.\%) }\end{array}$ \\
\hline $\mathrm{Ni}$ & 38.0 & 66.1 & 43.8 & 69.5 & 36.9 & 63.8 & 43.1 & 68.8 \\
$\mathrm{Cr}$ & 24.8 & 1.6 & 26.2 & 1.5 & 25.0 & 2.0 & 27.3 & 2.0 \\
$\mathrm{Al}$ & 3.6 & 13.7 & 3.2 & 13.2 & 4.1 & 15.6 & 3.6 & 15.0 \\
$\mathrm{Mo}$ & 2.4 & 0.1 & 2.6 & 0.1 & 2.5 & 0.3 & 2.7 & 0.2 \\
$\mathrm{Co}$ & 27.4 & 7.0 & 20.7 & 4.1 & 28.1 & 9.1 & 20.2 & 4.6 \\
$\mathrm{Nb}$ & 2.1 & 9.5 & 1.7 & 9.8 & 1.7 & 7.0 & 1.4 & 7.3 \\
$\mathrm{Ta}$ & 0.45 & 1.67 & 0.32 & 1.51 & 0.29 & 1.62 & 0.19 & 1.75 \\
$\mathrm{~W}$ & 1.29 & 0.12 & 1.36 & 0.12 & 1.36 & 0.19 & 1.36 & 0.18 \\
\hline
\end{tabular}

The results from Tables 3 and 5 were combined and plotted in Fig. 5 in order to better demonstrate the changes in the characteristic partitioning behavior of selected elements to the $\gamma$ and/or $\gamma^{\prime}$ phase. Overall, $\mathrm{Ni}$ is present in both the $\gamma$ and $\gamma^{\prime}$ phases, however, it preferentially partitions to the $\gamma^{\prime}$ phase. Although Cr, Mo, Co and W partition preferentially to the $\gamma$ phase, significant amounts of each are present in the $\gamma^{\prime}$ phase as well. As $\gamma^{\prime}$ formers, $\mathrm{Al}, \mathrm{Nb}$ and $\mathrm{Ta}$ preferentially partition to the $\gamma^{\prime}$ phase, however, due to the high overall $\mathrm{Nb}$ content in these alloys, a significant concentration of $\mathrm{Nb}$ was found in the $\gamma$ phase. Finally, Table 6 provides the values of the strengthening coefficients used for Eqs. 1 and 3. For the $\gamma$ phase, besides Mo and W, which are commonly used as $\gamma$ solid solution strengtheners and contribute 1015 and 977 $\mathrm{MPa} /$ at.fraction $^{1 / 2}$, respectively, $\mathrm{Ta}$ and $\mathrm{Nb}$ also exhibit high strengthening potency when present in the $\gamma$ phase contributing 1191 and $1183 \mathrm{MPa} /$ at.fraction $^{1 / 2}$, respectively. For the $\gamma^{\prime}$ phase, once again $\mathrm{Ta}$ and $\mathrm{Nb}$ serve as the most potent strengthening elements for this phase with 80 and 76 $\mathrm{MPa} /$ at.pct. 
Table 6. Strengthening coefficients for various elements.

\begin{tabular}{|c|c|c|}
\hline \multirow[b]{2}{*}{ Element } & \multicolumn{2}{|c|}{ Strengthening coefficients } \\
\hline & Y (MPa/at.fraction $\left.{ }^{-1 / 2}\right)$ & $\mathrm{Y}^{\prime}$ (MPa/at.pct) \\
\hline $\mathrm{Cr}$ & 337 & 7 \\
\hline $\mathrm{Al}$ & 225 & 0 \\
\hline Mo & 1015 & 16.8 \\
\hline $\mathrm{Fe}$ & 153 & - \\
\hline C & 1061 & - \\
\hline Co & 39.4 & 0 \\
\hline $\mathrm{Nb}$ & 1183 & 76 \\
\hline $\mathrm{Ta}$ & 1191 & 80 \\
\hline W & 977 & 25 \\
\hline $\mathrm{Hf}$ & 1401 & 140 \\
\hline $\mathrm{Ti}$ & 775 & 25 \\
\hline V & 408 & 8.2 \\
\hline
\end{tabular}

The APT phase composition measurements were used in Eqs. 1 and 2 to determine the degree of solid solution strengthening as a function of temperature for these experimental alloys. The solute strengthening constants are consistent with the values of parameters used in similar studies $[11,12,28]$ with values of $\mathrm{K}_{1}$ and $\mathrm{K}_{2}$ ranging from 68 to 72 and 0.18 , respectively. Since the shear modulus is unknown for these alloys, values for alloys with similar compositions were considered and a temperature dependent range of $46 \mathrm{GPa}$ to $86 \mathrm{GPa}$ was used that corresponded to $25^{\circ} \mathrm{C}$ to $800^{\circ} \mathrm{C}$ [29]. Eq. 3 was used to determine the strength as a function of temperature of the $\gamma^{\prime}$ precipitates using solute strengthening constants by Mishima et al. [11,22,23]. The fraction of $\gamma^{\prime}$ precipitates that will harden by solid solution strengthening was chosen to be any precipitate above $100 \mathrm{~nm}$ as Fig. 1 is modeled for such a scenario [27]. Fig. 1 was used in order to determine the CRSS from the friction stresses of the $\gamma$ matrix and the $\gamma^{\prime}$ precipitates due to solid solution strengthening. The calculated results are plotted in Fig. 6a, where the $\gamma$ strength is plotted along 
the left axis and shows a curve with diminishing strength as a function of temperature, while $\gamma^{\prime}$ strength is plotted along the right axis and shows a peak in the strength at around $700^{\circ} \mathrm{C}$. From Fig. 6a, the solid solution strength of the $\gamma$ matrix is highest for RRHT1 followed by RRHT4, RRHT2, while RRHT3 showed to be the weakest. For the $\gamma$ ' hardening, RRHT1 was predicted to exhibit the highest strength, followed by RRHT2, and with a slightly lower strength but grouped closely together. This was followed by RRHT4 and RRHT3. In addition, the strength of the constituent phases in a commercial polycrystalline, Ni-base superalloy, IN100 was calculated using the phase composition data obtained by Wusatowka-Sarnek et al. [30] and plotted in Fig. 6a for comparison. Compared to the RRHT alloys, the alloying content of IN100 is significantly lower and, as a result, contains $\gamma$ and $\gamma^{\prime}$ phases that are noticeably weaker.

Thermo-Calc predictions of the $\gamma$ and $\gamma^{\prime}$ phase compositions for each of the alloys, from Table 5, were also used to model the solid solution strengthening contributions to the $\gamma$ and $\gamma^{\prime}$ phases utilizing the same model used for the experimental data. To keep comparisons consistent, the same constants and alloy properties employed for calculating the strength from the APT data were used. For strengthening of the matrix, RRHT1 remained the strongest as the concentration of $\mathrm{Nb}$ present in the $\gamma$ phase for this alloy was the highest, Fig. $6 \mathrm{~b}$. The $\gamma$ phase strength curves for RRHT4 and RRHT2 are grouped together even though RRHT2 has a much higher Nb concentration. This discrepancy can be attributed to the higher Mo concentration of RRHT4, which also serves as a potent solid solution strengthener for $\gamma$. RRHT3, which has the lowest $\mathrm{Nb}$ concentration in the $\gamma$ matrix, was predicted to be the weakest. For the $\gamma^{\prime}$ hardening, RRHT1 and RRHT2 are again the strongest as $\mathrm{Nb}$ also serves to harden this phase with a strength coefficient of about $75 \mathrm{MPa} /$ at.fraction $^{-1 / 2}$. RRHT4 and RRHT3, which have a lower overall Nb composition are predicted to be modestly weaker, with RRHT3 having a slightly lower strength than RRHT4, which again could be attributed to the lower $\mathrm{Nb}$ concentration in its $\gamma^{\prime}$ phase. Finally, as a comparison, Thermo-Calc predictions for the $\gamma-\gamma$ ' phase compositions of IN100 were also used to 
estimate the degree of elemental strengthening and once again the temperature dependent strength for both $\gamma$ and $\gamma^{\prime}$ phases were much lower when compared to those in the RRHT alloys.

\section{Discussion}

High $\mathrm{Nb}$ content $\gamma-\gamma^{\prime} \mathrm{Ni}$-base superalloys were investigated in order to better understand the partitioning of the different elements and the resulting effect on the strength of the alloys. Control of the characteristic partitioning behavior in this class of alloys is particularly important as this will contribute to the formation of secondary precipitate phases such as $\delta$ and $\eta[16]$. Moreover, elements such as $\mathrm{Nb}$, Ta, and Ti may potentially partition to the $\gamma$ and/or $\gamma^{\prime}$ phase in varying degrees resulting in different levels of strengthening.

Comparing the experimentally measured and predicted volume fractions of the $\gamma$ and $\gamma^{\prime}$ phases in the experimental RRHT series of alloy, Tables 2 and 4, reveals that the predicted values are on average slightly higher by about $1-3 \%$. However, the differences are relatively minor and can be considered to be nominally identical when taking into account the standard deviation obtained from the measurements of the 10 regions of each sample.

From Fig. 5, the experimental partitioning behavior of each of the constituent elements can be compared to that of the partitioning calculated using the Thermo-Calc TCNI5 database. Overall, the Thermo-Calc predictions are close to the experimental results with similar general trends, but some noticeable differences are worth mentioning. The concentrations of W and Mo in the $\gamma^{\prime}$ phase were considerably lower in the Thermo-Calc predictions while the APT data revealed a stronger presence of those elements within the $\gamma^{\prime}$ phase. More importantly, $\gamma^{\prime}$ formers, such as $\mathrm{Ta}, \mathrm{Al}$ and $\mathrm{Nb}$ present major differences in the predicted partitioning behavior when compared to the results from the APT data. Al additions were predicted to have much higher solubility in the $\gamma$ phase and consequently the magnitude of the corresponding partition fractions are on average two 
times greater than those obtained by the APT results. Partitioning coefficients for Ta, while differing from alloy to alloy, tend to be higher in the Thermo-Calc predictions when compared to the actual data. Interestingly, $\mathrm{Nb}$ additions were predicted to exhibit a lower solubility in the $\gamma$ phase than expected and the corresponding partition fractions are therefore on average lower.

As expected the strength of the $\gamma$ matrix phase is highest at low temperatures and gradually decreases as a function of temperature, as described by Eq. 2, while hardening of the $\gamma^{\prime}$ phase exhibits a peak in the higher temperature ranges. From Table 6, it is apparent that for the $\gamma$ phase, besides additions of Mo and W, which can be added in small quantities to the alloy's composition, the most potent solid solution strengtheners are the $\gamma^{\prime}$ forming elements, $\mathrm{Ta}$ and $\mathrm{Nb}$, which contribute 1191 and $1183 \mathrm{MPa} /$ at.fraction $^{1 / 2}$, respectively. As alloying additions for Ni-base superalloys, the high density and cost of Ta limit its use in the alloys. Compared to $\mathrm{Ta}, \mathrm{Nb}$ is significantly lower in both cost and density. As a result, $\mathrm{Nb}$ additions may potentially be used to significantly increase the strength of Ni-base superalloys without incurring increases in cost or bulk alloy density. Referring to the results in Fig. 5, it is apparent that in the experimental alloys, RRHT1 has the highest concentration of Nb, followed by RRHT2, RRHT3 and RRHT4, respectively and therefore their strengths in Fig. 6a follow a similar pattern. Similarly for the $\gamma^{\prime}$ strengthening, $\mathrm{Nb}$ has a significant strengthening contribution and therefore the strengthening curves also directly correlate to the $\mathrm{Nb}$ content within the phase. Although some differences in the partitioning of elements exist, the resulting temperature dependent strength curves produced with data predicted by Thermo-Calc, Fig. 6b, are comparable to the curves calculated with experimental values, Fig. 6a. A more pronounced difference can be seen in the strength of the $\gamma^{\prime}$ phase, where the strengths calculated by Thermo-Calc are about $150 \mathrm{MPa}$ higher than the results calculated using the experimental data. This can be attributed to the higher degree of $\mathrm{Nb}$ partitioning to the $\gamma^{\prime}$ phase predicted by Thermo-Calc that results in a higher $\mathrm{Nb}$ concentration in the precipitates that significantly hardens the $\mathrm{Ni}_{3} \mathrm{Al}$ phase. Finally, contributions from elemental 
strengthening in the RRHT alloys are much higher when compared to a commercially used Nibase superalloy, IN100. Although IN100 has a higher Mo content, as well as additions of Ti and $\mathrm{V}$, which contribute to strengthen the $\gamma$ phase, it is still much weaker when compared to the $\mathrm{Nb}$ containing RRHT series of alloys. The observed differences are more pronounced for the $\gamma^{\prime}$ strength as $\mathrm{Ti}$ only contributes $25 \mathrm{MPa} /$ at.fraction $^{-1 / 2}$ to the hardening of $\gamma^{\prime}$, which is only approximately a third of the value for $\mathrm{Nb}$.

\section{Conclusions}

Based on the results and observations presented in this study, the following conclusions can be reported:

1. At elevated concentrations in the alloy composition, $\mathrm{Nb}$ atoms can serve as potent solid solution strengtheners for the $\gamma$ matrix phase while promoting the formation of $\gamma^{\prime}$.

2. When evaluating the temperature dependent properties of experimental Ni-base superalloys, phase composition data can be used along with strength models to estimate the degree of intrinsic compositional strengthening that exists within the constituent $\gamma$ and $\gamma$ 'phases.

3. For these experimental alloys, thermodynamic database models, such as Thermo-Calc with TCNI5, predicted phase compositions close to those obtained from APT. However, some dissimilarities in partitioning and $\gamma^{\prime}$ volume fraction were noted that resulted in significant differences between the predicted strength profiles.

\section{Acknowledgements}

Financial support for this work was provided by Rolls-Royce North American Technologies, Rolls-Royce Corporation, Rolls-Royce plc., and NSF-DMR-1006953. Additionally, the localelectrode atom-probe tomograph at the Northwestern University Center for Atom-Probe 
Tomography (NUCAPT) was acquired and upgraded with equipment grants from the MRI program of the National Science Foundation (grant number DMR-0420532) and the DURIP program of the Office of Naval Research (grant numbers N00014-0400798, N00014-0610539, N00014-0910781). NUCAPT is a Research Facility at the Materials Research Center of Northwestern University, supported by the National Science Foundation's MRSEC program (grant number DMR-1121262). Additional instrumentation at NUCAPT was supported by the Initiative for Sustainability and Energy at Northwestern (ISEN).

\section{References}

[1] Pollock TM, Tin S. Nickel-based superalloys for advanced turbine engines: chemistry, microstructure and properties. J Propul Power 2006;22:361-74.

[2] Furrer D, Fecht H. Ni-based superalloys for turbine discs. J Miner Met Mater Soc 1999;51:14-7.

[3] Sims CT, Stoloff NS, Hagel WC. Superalloys II. New York: Wiley; 1987.

[4] Decker RF, Sims CT. The Metallurgy of Nickel-base Superalloys. New York: Paul D. Merica Research Laboratory; 1972.

[5] Unocic RR, Viswanathan GB, Sarosi PM, Karthikeyan S, Li J, Mills MJ. Mechanisms of creep deformation in polycrystalline Ni-base disk superalloys. Mater Sci Eng A 2008;483:25-32.

[6] Unocic RR, Kovarik L, Shen C, Sarosi PM, Wang Y, Li J, et al. Deformation mechanisms in Nibase disk superalloys at higher temperatures. Superalloys 2008. Warrendale, PA: TMS; 2008.

[7] Locq D, Caron P, Raujol S, Pettinari-Sturmel F, Coujou A, Clément N. On the role of tertiary $\gamma^{\prime}$ precipitates in the creep behavior at $700^{\circ} \mathrm{C}$ of a PM disk superalloy. Superalloys 2004. Warrendale, PA: TMS; 2004.

[8] Reed RC. The Superalloys: Fundamentals and Applications. New York: Cambridge University Press; 2006.

[9] Donachie MJ, Donachie SJ. Superalloys: A Technical Guide. 2nd ed. Materials Park, OH: ASM International; 2002.

[10] Pollock TM, Field RD. Chapter 63 Dislocations and high-temperature plastic deformation of superalloy single crystals. Dislocat. Solids 2002;11:547-618.

[11] Kozar RW, Suzuki A, Milligan WW, Schirra JJ, Savage MF, Pollock TM. Strengthening Mechanisms in Polycrystalline Multimodal Nickel-Base Superalloys. Metall Mater Trans A 2009;40:1588-603.

[12] Roth HA, Davis CL, Thompson RC. Modeling Solid Solution Strenthening in Nickel Alloys. Metall Mater Trans A 1996;28:1329-35.

[13] Mignanelli PM, Jones NG, Perkins KM, Hardy MC, Stone HJ. Microstructural evolution of a delta containing nickel-base superalloy during heat treatment and isothermal forging. Mater Sci Eng A 2015;621:265-71. 
[14] Detrois M, Helmink RC, Tin S. Hot deformation characteristics of a polycrystalline $\gamma-\gamma^{\prime}-\delta$ ternary eutectic Ni-base superalloy. Mater Sci Eng A 2013;586:236-44.

[15] Detrois M, Helmink RC, Tin S. Microstructural Stability and Hot Deformation of $\gamma-\gamma^{\prime}-\delta$ Ni-Base Superalloys. Metall Mater Trans A 2014;45:5332-43.

[16] Antonov S, Detrois M, Helmink RC, Tin S. Precipitate phase stability and compositional dependence on alloying additions in $\gamma-\gamma^{\prime}-\delta-\eta$ Ni-base superalloys. J Alloys Compd 2015;626:7686.

[17] Detrois M, Antonov S, Helmink RC, Tin S. Precipitate Phase Stability in $\gamma-\gamma^{\prime}-\delta-\eta$ Ni-Base Superalloys. JOM 2014;66:2478-85.

[18] Ghosh G, Olson GB. Integrated design of Nb-based superalloys: Ab initio calculations, computational thermodynamics and kinetics, and experimental results. Acta Mater 2007;55:3281303.

[19] Olson GB. Computational Design of Hierarchically Structured Materials. Science 1997;277:123742.

[20] Gypen LA, Deruyttere A. Multi-component solid solution hardening. J Mater Sci 1977;12:102838.

[21] Parthasarathy TA, Rao SI, Dimiduk DM. A fast spreadsheet model for the yield strength of superalloys. Superalloys 2004. Dayton, OH: Wiley; 2004, pp. 887-96.

[22] Mishima Y, Ochiai S, Hamao N, Yodogawa M, Suzuki T. Solid Solution hardening of $\mathrm{Ni}_{3} \mathrm{Al}$ with Ternary Additions. T Jpn I Met 1986;27:648-55.

[23] Mishima Y, Ochiai S, Yodogawa M, Suzuki M. Mechanical Properties of $\mathrm{Ni}_{3} \mathrm{Al}$ with Ternary Addition of Transition Metal Elements. T Jpn I Met 1986;27:41-50.

[24] Totten GE, Xie L, Funatani K. Handbook of Mechanical Alloy Design. Boca Raton, Fl: CRC Press; 2003.

[25] Sharma CP, Bhargava AK. Mechanical Behaviour and Testing of Materials. Delhi, India: PHI; 2011.

[26] Weertman J. Dislocation Based Fracture Mechanics. Singapore: World Scientific; 1996.

[27] Rao SI, Parthasarathy TA, Dimiduk DM, Hazzledinet PM. Discrete dislocation simulations of precipitation hardening in superalloys. Philos Mag A 2004;84:3195-215.

[28] Butt MZ. Solid-solution hardening in dilute and concentrated alloys. Phil Mag Lett 1989;60:141-5.

[29] Collins DM, Stone HJ. A modeling approach to yield strength optimization in a nickel-base superalloy. Int J Plast 2014;54:96-112

[30] Wusatowska-Sarnek AM, Ghosh G, Olson GB, Blackburn MJ, Aindow M. Characterization of the microstructure and phase equilibria calculations for the powder metallurgy superalloy IN100. J Mater Res 2003:18;2653-63. 


\section{Figure captions}

Fig. 1. Effects of lattice friction stresses on yield stress reproduced with data from Rao et al. [27].

Fig. 2. FESEM images of the microstructures of RRHT1, RRHT2, RRHT3, and RRHT4.

Fig. 3. APT needles of (a) RRHT1, (b) RRHT2, (c) RRHT3, and (d) RRHT4.

Fig. 4. Thermo-Calc phase fractions in (a) RRHT1, (b) RRHT2, (c) RRHT3, and (d) RRHT4.

Fig. 5. Partitioning of the different alloy elements in (a) RRHT1, (b) RRHT2, (c) RRHT3, and (d) RRHT4 from experimental and Thermo-Calc generated data.

Fig. 6. Strength curves calculated from (a) experimental APT and (b) Thermo-Calc phase composition data. 


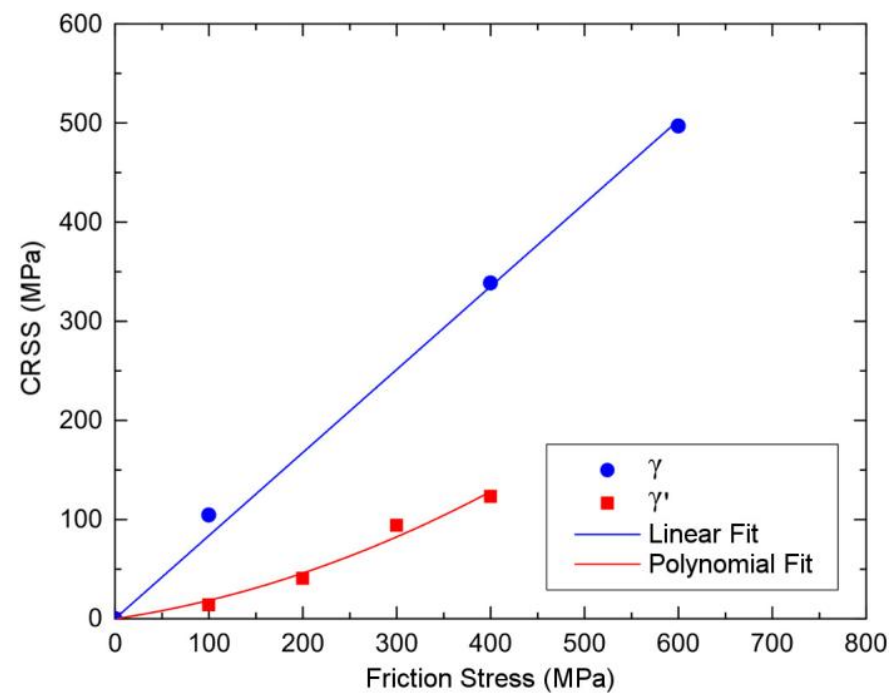

Figure 1 

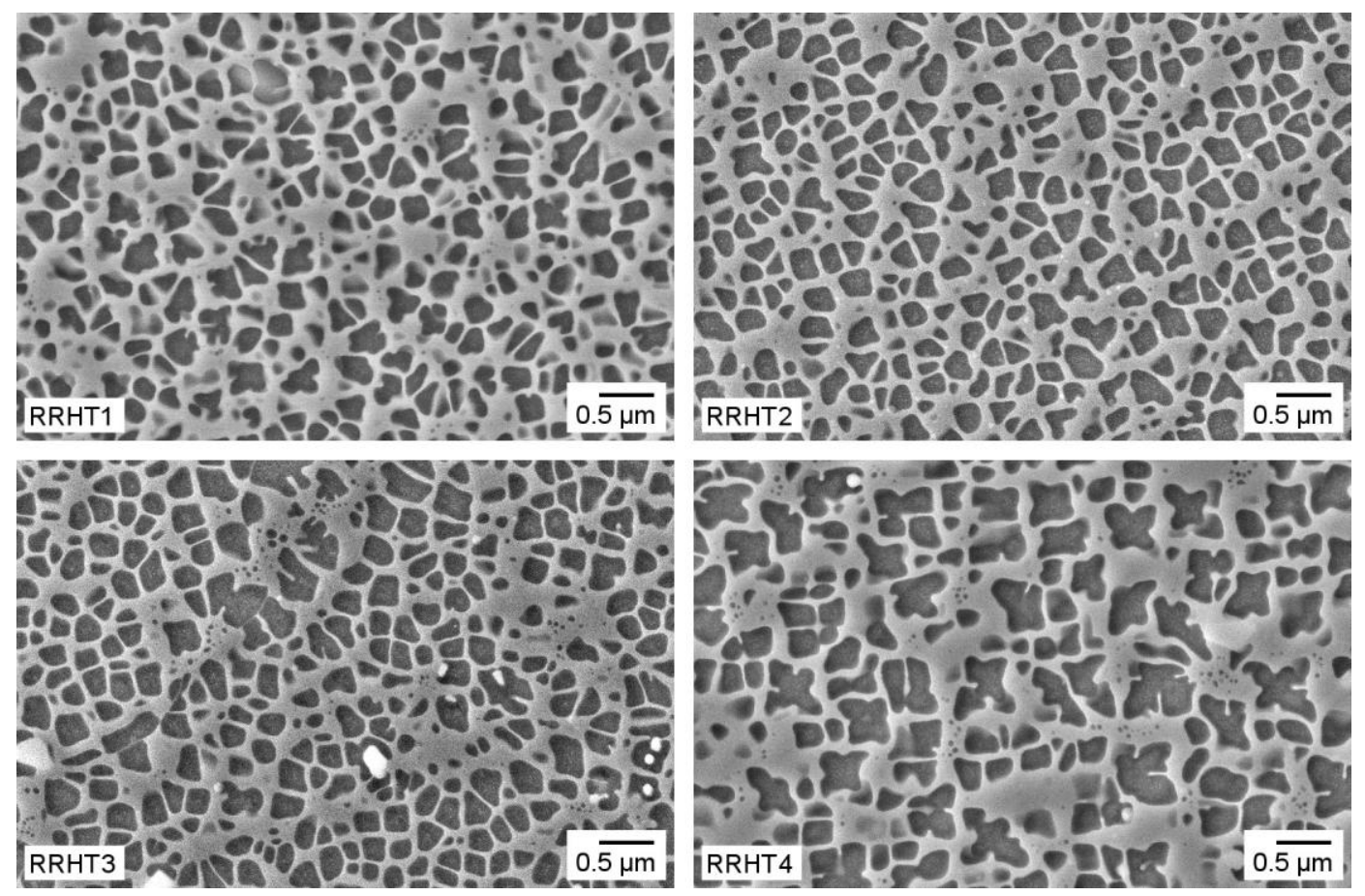

Figure 2 
(a)

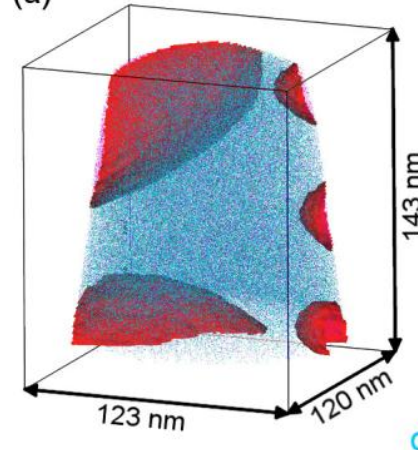

(c)

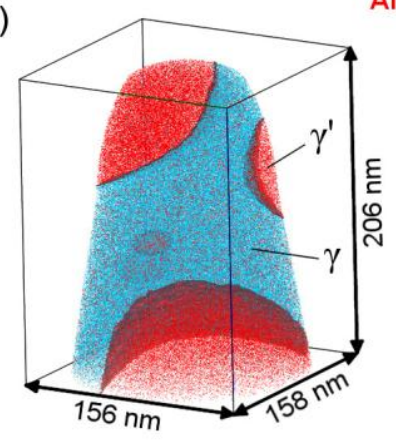

(b)

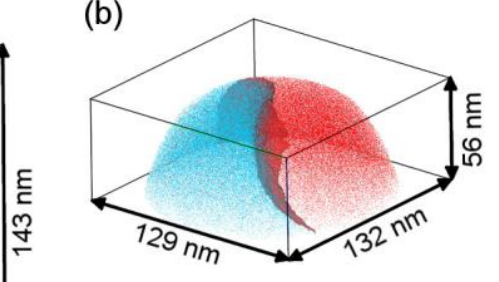

(d)

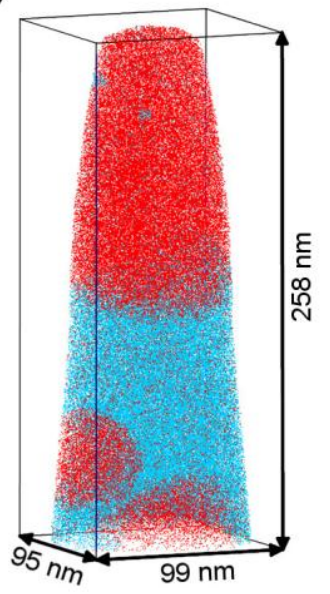

Figure 3 

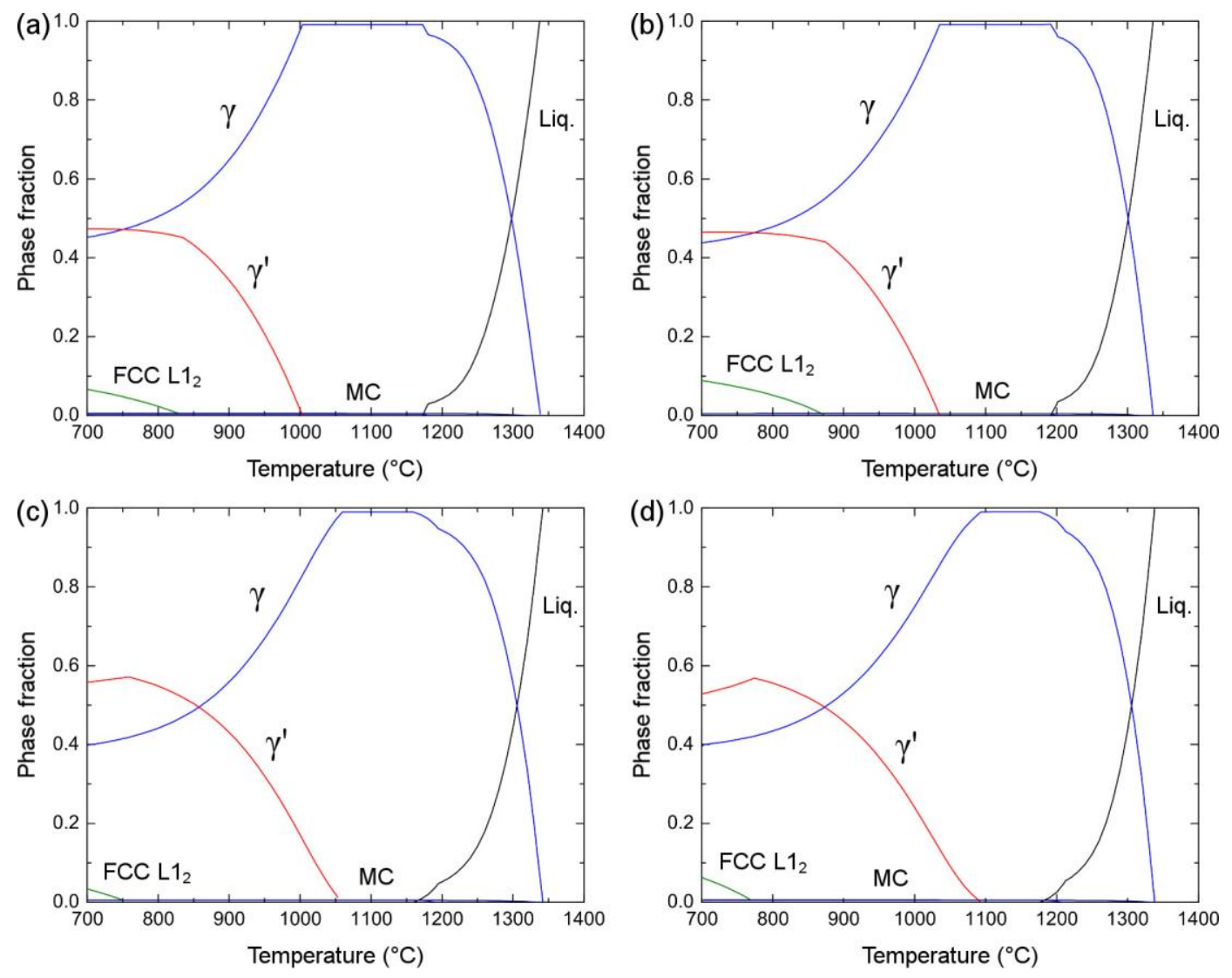

Figure 4 
$\square$ APT data $\square \Delta$ Thermo-Calc
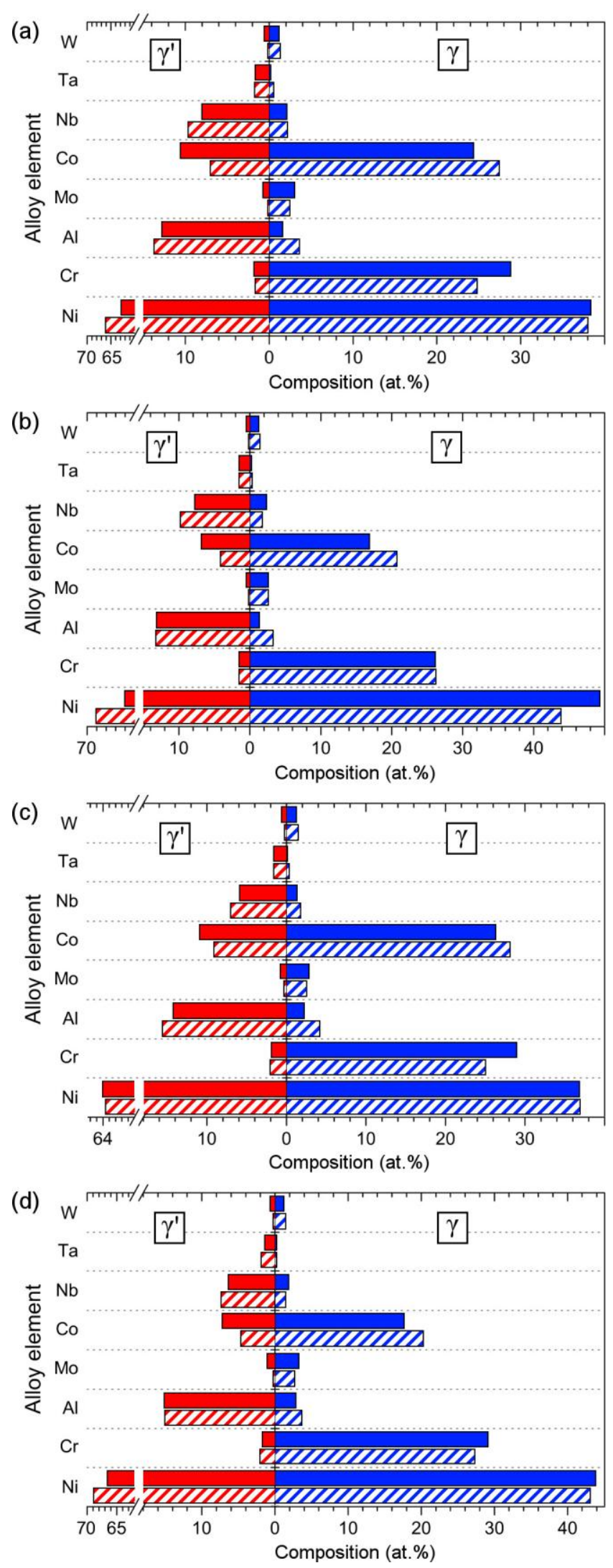

Figure 5 

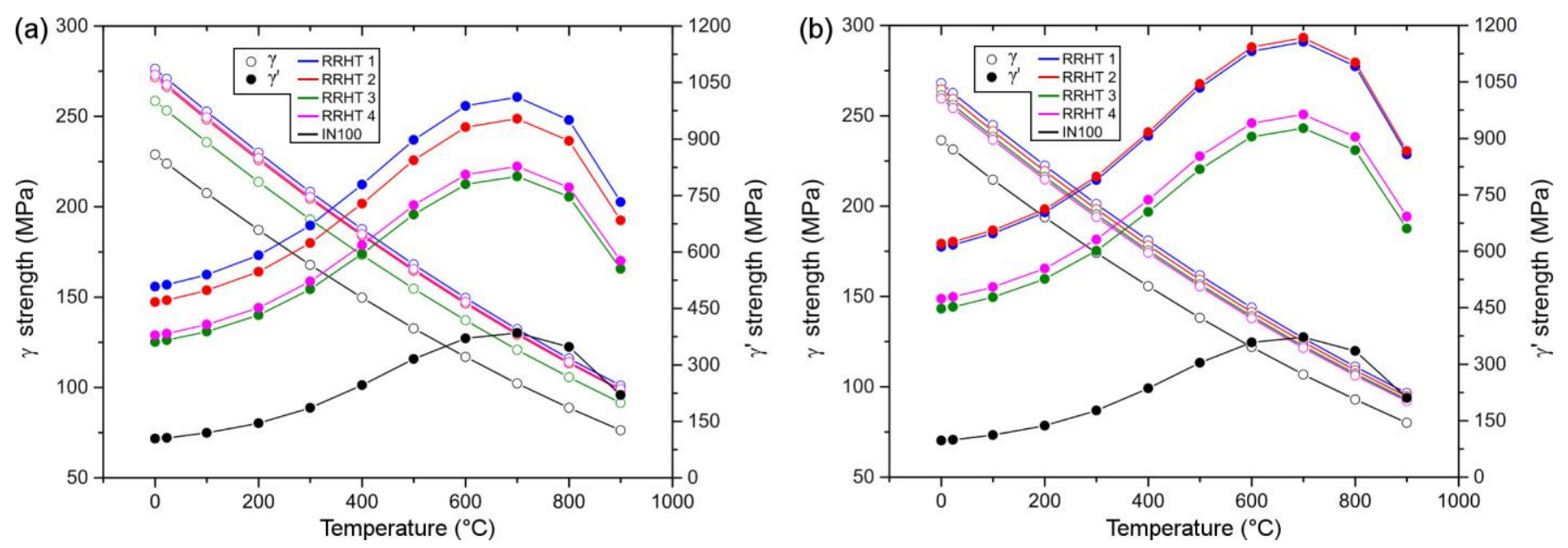

Figure 6 
Graphical Abstract
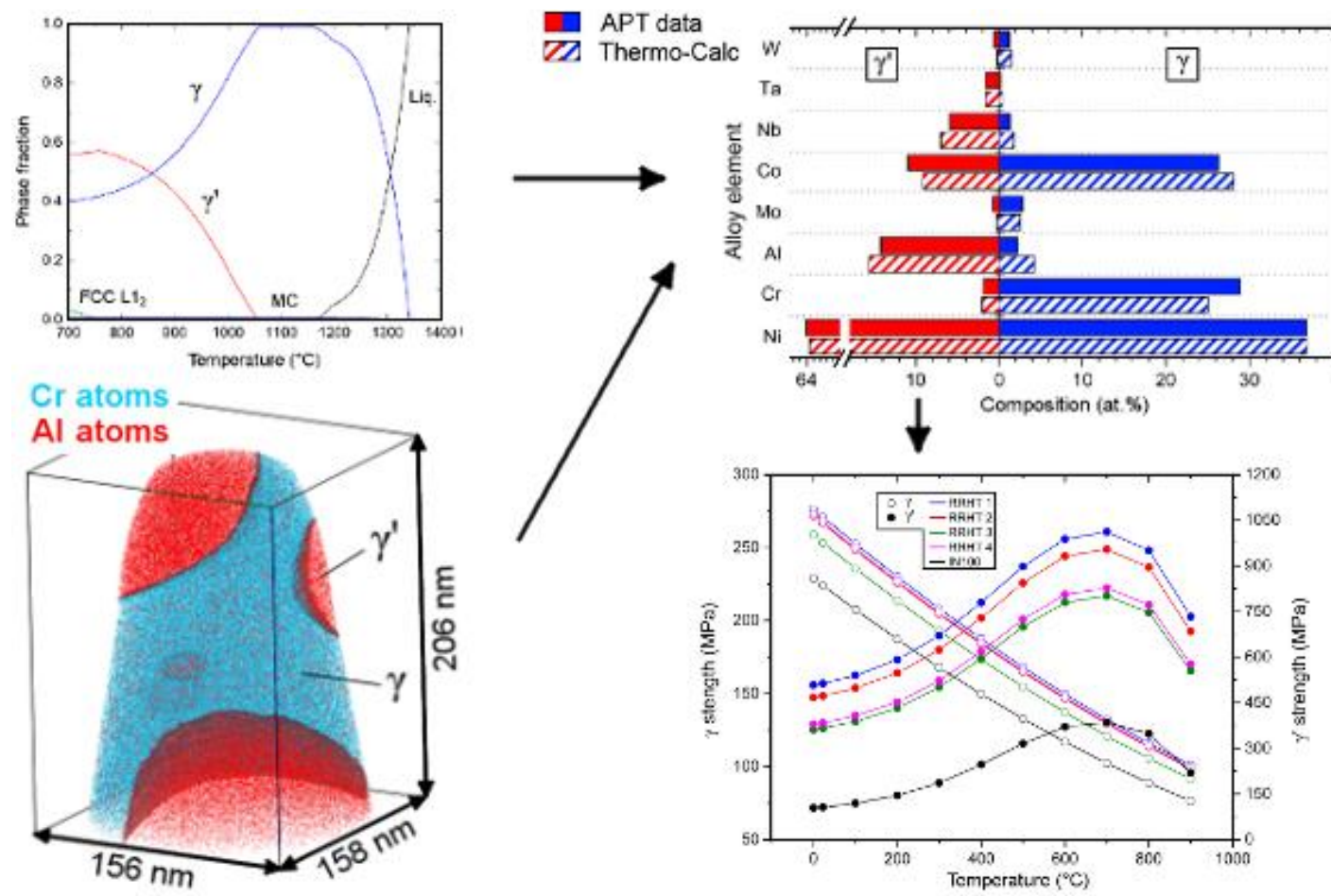